\title{
humanidades
}

Revista humanidades

Julio-Diciembre, 2015 •Volumen 5, número 2・ISSN 2215-3934•pp. 1-21

\section{La importancia de San Agustín y Santo Tomás de Aquino en la concepción cósmica y su influencia en los calendarios}

DOI: http://dx.doi.org/10.15517/h.v5i2.21215

\section{Héctor Miranda Fonseca}

Máster, profesor en la Sección de Filosofía y Pensamiento en la Escuela de Estudios Generales de la Universidad de Costa Rica.

Correo electrónico: lic_hector_cr@hotmail.com

Más sobre el autor:

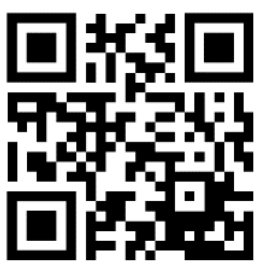

Todos los derechos reservados. Universidad de Costa Rica. Esta revista se encuentra licenciada con Creative Commons 


\section{La importancia de San Agustín y Santo Tomás de Aquino en la concepción cósmica y su influencia en los calendarios}

\section{Resumen}

Este artículo trata acerca de los aportes que hicieron San Agustín de Hipona y Santo Tomás de Aquino con respecto a la elaboración de calendarios y la influencia de importantes estudiosos en la estructuración del pensamiento de estos filósofos. También, se hace referencia a los postulados teóricos de estos autores, sus contraposiciones con relación a la ciencia y la teología, así como algunos aspectos históricos del contexto en que vivieron, con el propósito de entender su obra y la importancia de la Iglesia como institución rectora de una época.

Palabras clave: Tiempo, ciencia, Teología, Historia, calendario, intuición, intelecto.

\section{The importance of Saint Augustine and Saint Thomas Aquinas on the cosmic conception and his influence on calendars}

\section{Abstract}

This article is about the contributions that made St. Augustine and Saint Thomas de Aquino with respect to the development of calendars and the influence of important scholars in the structuring of the thought of these philosophers. Also, refers to postulated theorists of these authors, their contrasts in relation to science and theology, as well as some historical aspects of the context in which they lived, in order to understand his work and the importance of the Church as the governing body of an era.
Keywords: Time, science, Theology, History, calendar, intuition, intellect. 
La filosofía griega aduce que una de las características del ser humano radica en la constante pregunta sobre el porqué de las cosas. En la búsqueda de respuestas a esas interrogantes, la observación desempeñó una función esencial. Por eso, la bóveda celeste constituyó una fuente primordial para contestar a todo lo relacionado con los movimientos de los astros y su posible incidencia en los asuntos humanos vinculados con el yo y la naturaleza.

Históricamente se sabe que los griegos fueron pueblos dedicados a la navegación, esto les permitió conocer y transmitir su cultura a otras latitudes. Así pues, se conoce su influencia sobre el norte de África, el Oriente Medio y por supuesto en todo el sur del continente europeo. Por eso, la península griega fue objeto de múltiples migraciones como la de los aqueos, jonios y dorios para citar algunos (Martín, 1996).

De acuerdo con lo anterior, la geografía fue una ciencia de vital importancia en la expansión económica y cultural de los helenos.

Durante ese afán indagatorio, unido a su vida material, surgió la preocupación por medir el tiempo. En ese sentido, la observación del cosmos fue esencial para confeccionar instrumentos que les permitieran medir el tiempo y vincularlo al espacio. Se elaboraron, entonces, calendarios que se fundamentaron esencialmente en la posición relativa presentada por los astros en relación con la Tierra. 
La confección de calendarios es muy antigua, esta se remonta a los esfuerzos que hicieron sacerdotes y astrónomos para ayudar a comunidades en sus necesidades básicas y labores cotidianas, además, para la celebración de festividades religiosas. Así, la medición del tiempo se asocia con la creciente de los ríos, con los movimientos de la luna y, posteriormente, con otros astros.

Un aspecto relevante en el proceso de calendarización fue el sedentarismo del ser humano, ya que surgen actividades como el pastoreo de animales, la siembra y la recolección de cosechas que obligaron a establecer una división entre el día y la noche. Durante la recolección de datos empíricos, se detectó que algunos días eran más largos y otros más cortos, lo mismo ocurría con sus noches. Este hecho coincidió con la revolución agrícola, alrededor de diez mil años a. C., en pueblos como el mesopotámico, el egipcio, hindú, chino y africano (Rivero, 1976).

Es interesante señalar, por lo apuntado en líneas atrás, que la calendarización pronto tuvo un trasfondo religioso, porque muchas culturas comenzaron a creer que los astros eran una suerte de dioses y que determinaban lo que sucedía en el mundo físico de los humanos.

Con la aparición de la filosofía en Grecia, se rompe este paradigma y se origina una visión en la cual la religión y la ciencia, de manera singular, se separan. Dicha situación se extendió en todo el occidente europeo, por la influencia de los helenos y su labor marítima y comercial característica, como se anotó anteriormente. 
Los filósofos más preclaros en profundizar esta división fueron Platón y Aristóteles, como se puede apreciar en sus obras y enseñanzas, en las cuales sitúan a los dioses en un lugar distinto a la ciencia y al conocimiento verdadero, o epistemología, en términos platónicos.

No obstante, pasaron muchos años antes de que esta concepción se universalizara. En Occidente, especialmente en Europa, el ligamen cienciareligión se puede apreciar claramente en los planteamientos filosóficos de Santo Tomás de Aquino y San Agustín de Hipona que denotan un grado de madurez respecto a la visión griega.

San Agustín de Hipona nació en Tagaste, norte de África, en el año 354; y murió en el año 430. Se considera el filósofo más importante de la Iglesia cristiana antigua.

El padre de San Agustín era un pagano y su madre, por el contrario, una mujer cristiana. Tras constantes observaciones, estos reconocieron el gran talento de su hijo en el campo literario y destacaron su agudeza mental. Por lo anterior decidieron enviarlo a la Escuela de Cartago, cuando apenas tenía 16 años; en dicha institución estudió Retórica y Derecho.

Cabe mencionar que Cartago era una ciudad que albergaba los principales centros de aprendizaje de la época y los estudios de corte pagano constituían la tónica principal de su currículo; sin embargo, la introducción del pensamiento cristiano ya aparecía en algunos textos de Ireneo y otros escritores conocidos en la historia, como la patrística cristiana cuyos inicios datan del siglo segundo después de Cristo.

\section{San Agustín de Hipona}


Se cree que San Agustín, por todas estas influencias vividas en Cartago, abrazó filosofías paganas como el maniqueísmo, alrededor del año 373. El maniqueísmo es un pensamiento procedente de un personaje persa conocido como Mani o Manes, alrededor del siglo II después de Cristo. Este autor enseñó un estricto dualismo en el que la luz y la oscuridad están en un conflicto eterno; la luz adquiere un significado de paz, convivencia armónica u Ormuz; por su parte, la oscuridad constituye un debate, una lucha o Ahrimán. De ahí que para él, el universo es el resultado de confrontaciones entre mundo de las tinieblas y la luz, de esa manera, surge la vida.

Aunque Manes rescató la figura de Jesús presentado por el cristianismo, le adjudicó tradiciones budistas y otros aspectos de la ideología persa, otorgándole así, un perfil que dista mucho de la pureza desde la óptica cristiana (Bermejo, 2008).

Según narra la historia, cuando San Agustín se convirtió al cristianismo, ya tenía una experiencia basta en los campos filosóficos y religiosos. No obstante, la influencia de otros pensadores griegos y latinos fue esencial en la configuración de su pensamiento, que se enriqueció con la filosofía neoplatónica, pitagórica, estoica, epicúrea, así como con su relación con Cicerón.

Para entender el pensamiento de San Agustín es importante conocer acerca del contexto en que se desarrolló este filósofo. Al respecto, se debe indicar que en el momento de su nacimiento y de su muerte, el Imperio Romano se encontraba en decadencia, porque, según los historiadores, el populacho en las ciudades aumentó, así como la esclavitud. Esta situación incentivó la 
lucha de clases que aunada a la corrupción política creciente, al derroche y al excesivo lujo, tanto del Emperador como de su nobleza, aceleraron la caída del Imperio.

Sumado a lo anterior, la extensión territorial del Imperio requería de gran cantidad de soldados, lo que implicó un gasto económico muy grande, pues ellos eran esenciales para el cuido de las fronteras y el mantenimiento de la paz, tanto interna como externa. Dichos soldados se encargaban de vigilar los roces entre las distintas culturas que conformaban el Imperio; asimismo, controlaron la violencia y los ataques de pueblos enemigos que intentaban saquear las zonas de riqueza.

En el aspecto económico, fueron varias las causas que repercutieron en el derrumbamiento del Imperio. Algunas de estas fueron el aumento creciente en los impuestos; la implementación de una economía de trueque, porque la moneda circulante disminuyó; el agotamiento de las tierras por el excesivo cultivo; y la declinación de todo el sector industrial y comercial, lo cual motivó a un aumento en la servidumbre de los ciudadanos quienes, en lugar de realizar labores productivas, se dedicaron a prestar servicios a la nobleza.

En este escenario apareció el pensamiento de San Agustín, producto en parte de la situación social e histórica antes mencionada. Además, en el año 410, Roma fue dominada por tribus norteñas que se dieron a la tarea de saquear el Imperio Romano y después regresaron a sus lugares de origen. Este hecho, sumado a lo expuesto anteriormente, creó una polémica entre los paganos que consideraban que la caída de Roma fue resultado de la cristianización del Imperio el año 323, específicamente durante el gobierno del Emperador Constantino. 
El pensamiento agustino parte de esa polémica y pretende demostrar que la caída de Roma no es producto del cristianismo. Así, Agustín de Hipona se dedicó a escribir una obra majestuosa, conocida como la Ciudad de Dios. En este texto, intenta rechazar los argumentos de aquellas personas que sostenían que si Roma hubiera continuado con el paganismo, se hubiera evitado su derrumbe como Imperio.

En esta obra, San Agustín plantea que la ciudad terrena debe adecuarse a la ciudad celestial, cosa que no hizo Roma, de ahí la caída de su Imperio. Dicho argumento fue fatídico, sobre todo para el desarrollo independiente de la ciencia, pues deja entrever que todo lo que el hombre realice debe ser cotejado con el texto bíblico y la tradición de la Iglesia Católica.

Anteriormente se mencionó que los griegos separaron religión y ciencia. Los planteamientos agustinos que mantienen metodológicamente la división entre ciencia y religión no logran dar continuidad a la postura helénica; por el contrario, más bien, supeditan la ciencia a la religión.

Esta situación resultó absolutamente natural en su momento, porque era imposible, para los lectores de la Biblia, entender una estructura del universo distinta a la común de su tiempo, como se puede observar en el siguiente texto bíblico: "Sol detente en Gabaón; y tú luna en el valle de Ajalón. Y el sol se detuvo y la luna se paró" (Josué, 10:12-13). Esto constituye una muestra del pensamiento que privaba en aquella época; una tierra estática y geocéntrica. Dicha concepción fue la teoría planteada por Aristóteles, y avalada por Platón, que sirvió de base a la Iglesia Católica. Posteriormente, Copérnico, en el año 1543, escribió su obra Sobre las revoluciones de los cuerpos celestes, en la que se sostiene una teoría heliocéntrica, idea que tuvo que ser retomada por la cuando se elabora el calendario gregoriano. 
El pensamiento de San Agustín fue esencial para que la Iglesia no dejara de lado la visión científica y su vinculación con la Biblia. Se evita, entonces, un desarrollo independiente de la ciencia, porque tanto las observaciones astronómicas como de otra índole, esenciales en la elaboración de los calendarios, tuvieron que ser adecuados a los textos sagrados, en virtud de que, como se indicó en párrafos anteriores, los sacerdotes se esforzaron por las mediciones del tiempo para la celebración de festividades religiosas.

Dentro de las ideas de San Agustín destaca una asimilación del pensamiento de Platón, con algunas variantes, por ejemplo, la no creencia en la reencarnación. Además, el pensamiento maniqueo, con la dicotomía indisoluble entre lo bueno y lo malo, permeará a este filósofo; de ahí que, propone la idea de un hombre dicotómico, compuesto de alma y cuerpo. El alma en el hombre es la parte superior y la buena, mientras que el cuerpo es material e inferior, y es en este donde se radica el pecado, pues es la parte mala.

En materia de conocimiento, San Agustín señala la iluminación divina como un proceso continuo realizado por Dios en cada persona. No obstante, por ser un elemento divino, pasa por el filtro de lo que diga la Iglesia, tanto por su tradición, como por las exigencias bíblicas. Lo anterior atañe, además, a todo el conocimiento científico, partiendo del hecho de que Dios es el padre del conocimiento. 
Por todo lo expuesto, se puede decir que tanto la ciencia como la epistemología se fundamentan en una antropología filosófica; para San Agustín la ciencia y todo el conocimiento está impregnado de una atmósfera religiosa. Por eso, su pensamiento está indisolublemente ligado a lo teológico y filosófico, la ciencia se encuentra subordinada a la religión. En la confección de los calendarios, entonces, se aprecia un distanciamiento a la ciencia objetiva y un acercamiento a la concepción de tiempo y espacio presente en el texto bíblico.

Tomás de Aquino nació en Roccaseca, Italia, en el año 1227 d. C.; y murió en la Abadía de Fossanova en 1274. Su genealogía lo vincula con una familia noble conocida como los Condes de Aquino.

\section{El pensamiento de Santo Tomás de Aquino}

Su primera instrucción la realizó en Monte Cassino, Italia. En el año 1243, ingresó en la Orden de los Padres Predicadores Dominicos, llamados así en honor a Santo Domingo de Guzmán. Posteriormente, se convirtió en el representante típico de la escolástica medieval que trataba de utilizar, en el fundamento de los dogmas cristianos, las teorías de pensadores antiguos, especialmente las de Aristóteles. De ahí que, a partir del siglo XIII se consideró una autoridad en la filosofía y en la ciencia, llegó incluso a ostentar el título de Doctor, al igual que San Agustín de Hipona.

La escolástica medieval, como corriente de pensamiento, intentaba colocar un sustento filosófico como base a cualquier propuesta religiosa. En este sentido, Santo Tomás Aquino puso, como punto de partida en su pensamiento, la afirmación de la subordinación de la fe al conocimiento empírico, dejando claro que la fe y la ciencia no deben contraponerse, 
sino suplementarse. Por eso, su filosofía parte de los planteamientos aristotélicos acerca de la forma y de la materia; les otorga una interpretación religiosa.

Los planteamientos de Santo Tomás se contraponen a los de San Agustín. Así, ante el conflicto entre ciencia y religión, para San Agustín la fe adquiría relevancia, mientras que San Tomás buscaba una respuesta científica que no objetara los postulados bíblicos.

La vida del Aquinate se destaca por la defensa de los intereses feudales eclesiásticos. En ese sentido, comparte la opinión de que existen personas superiores, como los cristianos, y aquellos que, aunque fueron creados libres, por su pecaminosidad deben ser gobernados en el mundo cristiano por los más virtuosos y profesantes de dicha fe. Esa posición se puede apreciar claramente en el capítulo Derecho de Gentes (Ius Gentium) de su obra Summa Teológica. En el apartado supra mencionado sostiene que la esclavitud es un hecho natural, por eso, él se convierte en un defensor de la desigualdad y de la jerarquía feudal, a tal punto, que las Autoridades Eclesiásticas le otorgaron el Doctorado Angelicus, en el Concilio de Lyon.

En la vida de este filósofo figura su maestro Alberto Magno, quien se preocupó por enseñarle las nuevas corrientes que habían llegado a Europa. Dichas corrientes alcanzaron España por medio de los árabes, gracias al Califato de Nueva Granada que inició su desarrollo en el año 711 d. C.; destacan cuatro períodos importantes (711- 1031, 10311090,1090-1231,1231-1492) (Villa-real, 2003). 
Ahora bien, las obras de Aristóteles se desconocían en el continente europeo. Es gracias al rescate que hicieron los árabes y a las traducciones realizadas por el médico y filósofo Averroes, que Tomás de Aquino las asimila e incorpora al pensamiento cristiano (Marín, 2006).

Este filósofo no solo se destacó en el campo eclesiástico, sino también en el académico. Así pues, fue instructor en la ciudad de París, donde fue colega de San Buenaventura; también fungió como maestro en Roma y en Nápoles. Se dice que Carlos D'anjou lo introdujo en los Estudios Generales.

Su labor intelectual fue basta. Entre sus obras más importantes destacan los comentarios a la Metafísica, La Ética a Nicómaco y De Anima de Aristóteles. Después de realizar estos comentarios, inició sus dos obras más importantes, a saber: Summa Theológica y la Summa Contra Gentes. Se conocen, además, muchos opúsculos, por ejemplo, "El ser y la esencia" y "El mundo eterno".

Para entender su pensamiento, es importante conocer lo que aconteció en Europa durante los siglos XII y XIII. Esta se encontraba enmarcada en el feudalismo, según la historia. En el aspecto económico, las relaciones sociales imperantes fueron producto del desarrollo sociohistórico, en el cual toda la vida social e intelectual estaba bajo la sombra del clero. Por lo anterior, la escolástica religiosa estaba presente en todas las formas culturales, de manera que, aún en la vida económica, los tratados teológicos encontraban asidero. 
Por lo anterior, para Tomás de Aquino resultaba justo y necesario que la sociedad feudal tomara como fundamento el derecho divino, de esa manera, justificar que la propiedad era un régimen necesario y racional. En ese contexto, los esclavos eran considerados como siervos de la gleba, pero en lo sustancial mantenían su condición esclavista.

No obstante, con relación al esclavismo antiguo, Aquino afirmaba que el alma del esclavo era libre y por eso el amo no tenía derecho a darle muerte. Consideraba indigno el trabajo manual, por estar vinculado al cuerpo humano; por el contrario, el trabajo intelectual era noble, pues se vinculaba con el alma racional. Esta dicotomía, según Aquino, constituía la base de la jerarquía social. La separación entre el trabajo físico e intelectual fue un instrumento que sirvió para establecer diferencias entre la jerarquía feudal, pues la persona con mayor riqueza formaba parte de un eslabón superior en los estamentos feudales.

No se debe olvidar que el régimen de producción feudal surgió en Europa Occidental por el resultado de la confluencia y fusión de dos procesos antagónicos. Por un lado, la decadencia del modo de producción esclavista; por otro lado, el desarrollo de la plebe en la agricultura en forma de arrendatarios adscritos al señor feudal, no en el sentido de esclavos, tal como se concebía en la antigüedad, sino como campesinos que debían entregarle al señor feudal parte de sus cosechas. En esta misma forma de producción se desarrolló la agricultura en gran manera, primero a partir de una propiedad comunal y luego, con la propiedad privada de la tierra. 
La tenencia de la tierra fue una medida que sirvió para ubicar a las personas en la escala social. Si bien este período feudal, por su desarrollo, se puede considerar más evolucionado económica y socialmente que el esclavista, las relaciones sociales eran de dependencia personal del campesino con el señor feudal dueño de la tierra. Este último tenía derecho a vender y comprar a sus siervos, ya que ellos, por la estructura social, estaban ligados a las tierras que se vendían. Lo anterior no deja de ser una forma oculta de esclavitud, dicha condición se retrata literariamente en algunas obras de León Tolstoi, en el caso de Rusia.

En esta escala socioeconómica, además de la riqueza del señor feudal, existía también una propiedad individual del campesinado y del artesano sobre los artefactos de producción: animales, instrumentos de labranza y otras herramientas.

El sistema feudal desarrolló varias innovaciones de carácter técnico, por ejemplo, la prensa de lagar, el molino de viento, el aumento de la fuerza animal en labores de labranza y agricultura, así como un mayor conocimiento de la arvicultura, la viticultura y la oleicultura. Se introdujeron, además, nuevos cultivos como los cereales, variedades de árboles frutales y se aplicó la rotación de las siembras mediante el sistema de las tres hojas.

En el mundo económico feudal, el hecho de que el artesanado, y posteriormente el comercio, experimentaran una separación y se transformaran en actividades independientes, provocó un gran 
desarrollo de las fuerzas productivas. De modo que a partir del siglo XI, las ciudades de Europa Occidental fueron reviviendo paulatinamente, porque aunque existían desde los tiempos del Imperio Romano. Estas experimentaron una decadencia poblacional y una reducción de su territorio por las actividades agrícolas. Asimismo, a su lado surgieron otros pueblos que se poblaron más que en la época de la esclavitud y se convirtieron en centros artesanales y comerciales; por lo tanto, en una fuente de riqueza considerable.

Conjuntamente con la rehabilitación de ciudades, los artesanos perfeccionaron sus técnicas e instrumentos, como los hilares que cambiaron el huso por la rueca y después por la rueda; el telar vertical por el horizontal movido por un pedal. Estas innovaciones ayudaron al florecimiento de la industria, porque también se inventaron máquinas que realizaban uno a dos trabajos al mismo tiempo, lo que condujo a la especialización artesanal que, posteriormente, se constituyó en la base del desarrollo capitalista de producción.

Todo este desarrollo urbano y comercial abrió espacio al florecimiento cultural reflejado en una civilización más avanzada, que por supuesto, requería de una justificación intelectual. En ese sentido, toma relevancia la figura de Tomás de Aquino, porque ante la introducción de las corrientes averroístas fundamentadas en la filosofía de Aristóteles, se produjo un enfrentamiento con el pensamiento de San Agustín, que había predominado desde el siglo V a. C. hasta el siglo XII. Esto por cuanto la concepción filosófica agustina sobre el conocimiento, aducía que Dios era su fuente y contradecía la filosofía 
de Aristóteles, sustentada en que el origen primordial del conocimiento radicaba en los sentidos. Dicha posición aristotélica distanciaba a la Teología de la epistemología y si esta contradicción no se resolvía intelectualmente con cuidado, podía aumentar el descontento entre la Iglesia y los señores feudales.

Ante esta perspectiva, Santo Tomás realizó una obra majestuosa basada en los fundamentos aristotélicos, logrando compatibilizar algunos de estos con la religión, especialmente, al proponer la idea de la complementariedad que implica una conjunción del saber racional con la Teología. Esto con el fin de encontrar una fundamentación más racional al pensamiento cristiano, de esa manera, lograr que la Teología respondiera a las exigencias racionales de la filosofía y de la ciencia.

Sin embargo, este tipo de separación no fue del todo radical, pues tanto en San Agustín como en Santo Tomás, la teología estaba siempre en un lugar predominante. Si bien en el pensamiento de este último se denota una mayor autonomía, estas disciplinas no podían excluirse totalmente, porque la ciencia debía ser un complemento de la Teología. Es decir, bajo esa premisa, Tomás de Aquino logró explicar los ciclos y epiciclos, que eran una variación de la idea de esferas concéntricas de Aristóteles.

Tomás de Aquino siguió pensando en una Tierra estática y que lo perfecto era lo inmóvil, manteniendo a Dios, de alguna manera, como un ser completo que no debía ir hacia ningún lado para obtener su perfección, pues ya en sí lo era. En ese aspecto, el rescate de los sentidos realizado ya por Aristóteles, fue la base de Santo Tomás, de allí que a su 
filosofía se le llame Aristotelismo cristiano. No obstante, es en el campo de la metafísica donde este autor innova, pues no solo intenta demostrar que la caída del Imperio Romano no fue por causa del cristianismo, ya que, según él, el cristianismo y la cultura europea eran superiores a cualquier otra. Así, el carácter racional y su componente sobrenatural, hacían de Occidente una cultura superior a la árabe y a cualquier otra cultura. Su preocupación por la cultura árabe, se debe a la gran influencia que esta tenía en su época, de ahí su deleite por el estudio de diversas culturas.

A diferencia de San Agustín, que plantea que el conocimiento se consigue por iluminación especial de Dios, Santo Tomás sostiene que este empieza con los sentidos. Así, en el proceso de abstracción el hombre llega al conocimiento intelectual gracias a la doble acción de atraer, por un lado, las cualidades concretas de los seres o entes materiales a través de los sentidos; y por otro, el intelecto agente, que lo vincula con Dios. No logra, entonces, disolver definitivamente la dicotomía entre la Teología y la Ciencia, porque el intelecto agente, al ser superior por su sobrenaturalidad, debe supeditar lo adquirido por los sentidos a la revelación divina.

A partir de estos pensamientos tomistas es entendible que la inquisición persiguiera a los científicos; además, que Osiander, en el prefacio de la obra de Copérnico Sobre las revoluciones de las esferas celestes, afirmara que lo dicho por Copérnico en su libro era solamente una hipótesis. Con dicha afirmación, se evitó el rechazo de la obra copernicana y se congració con las entidades eclesiásticas. De igual forma, se explica el juicio a Galileo Galilei, quien trató de convencer a las Autoridades Eclesiásticas de Roma de que el verdadero sistema para explicar el cosmos era el copernicano y no el aristotélico. 
No era un momento apropiado para introducir cambios en la Iglesia que se alejaran de la interpretación literal de la Biblia. Tampoco para que los teólogos expusieran sus planteamientos, entre ellos Tomás de Aquino que llegó a ser proclamado por el Papa León XIII en su Encíclica, como el maestro de toda la Filosofía y Teología.

A la luz de los pensamientos de San Agustín y de Santo Tomás, era entendible el accionar de la Iglesia y del Tribunal de la Inquisición cuando descalificó la teoría copernicana sobre la estabilidad del Sol y el movimiento de la Tierra. Estos planteamientos eran considerados absurdos y falsos, a pesar del aval que les diera Galileo, porque eran contrarias a las Sagradas Escrituras. La propuesta de que la Tierra no era el centro del mundo y que se movía constantemente, fue considera absurda, filosóficamente falsa y teológicamente errónea para la fe.

En ese sentido, hubo que esperarse hasta el siglo XVI para que la Iglesia ampliara su visión y aceptara, parcialmente y por conveniencia, las propuestas copernicanas. De esa manera, corregir el calendario Juliano, en el cual no concordaba la celebración de la semana santa con el equinoccio de primavera. Este desfase provocaba problemas en la calendarización litúrgica, así como en una sociedad que estaba experimentando cambios en su visión de mundo; por lo tanto, lo teológico ahora pasaba por el filtro de lo racional, los dogmas eclesiásticos y sus rituales podían perder sentido si no se hacían dichas correcciones. 
De lo expuesto anteriormente, se concluye que la función que desempeñaron los autores supra citados en la confección de calendarios y defensa de los intereses eclesiásticos fue ardua.

Son muchos los aportes filosóficos de ambos pensadores. Aunque a primera vista no se les encuentra una relación directa con los calendarios, cuando se observa la justificación teológica que hacen del geocentrismo y del heliocentrismo, resulta imposible no deducir de sus postulados teóricos efectos en la medición del tiempo, porque el heliocentrismo permite un mejor establecimiento de fechas importantes para la Iglesia, por ejemplo, la Semana Mayor. Así, se optimiza la programación de actividades que enriquecen el calendario litúrgico y fomentan la religiosidad en una sociedad que tenía su mirada puesta en el teocentrismo y se debatía entre los postulados científicos y los teológicos. 
Aristóteles. (1973). Obras Completas. Madrid: Editorial Aguilar.

Referencias

Aristóteles. (1996). Acerca del cielo, Meteorológicos. Madrid: Editorial Gredos. bibliográficas

Aquino, Tomás. (1950). Summa Teológica. Madrid: Biblioteca de Autores Cristianos.

Aquino, Tomás. (2007). Summa contra Gentes. Madrid: Biblioteca de Autores Cristianos.

Bruno, G. (1981). Sobre el infinito y los mundos. Madrid: Editorial Aguilar.

Castro Alonso, M. (1903). Colección completa de las encíclicas de Su Santidad León XIII. Valladolid: Casa editorial Cuesta.

Capánaga, Victorino. (1974). Agustín de Hipona. Maestro de la Conversión cristiana. Madrid: Editorial Biblioteca de Autores Cristianos.

Copérnico, Nicolás. (1982). Sobre las revoluciones (de los orbes celestes). Madrid: Editora Nacional.

Copérnico, Digges Galilei. (1983). Opúsculos sobre el movimiento de la Tierra. Madrid: Editorial Alianza.

Copleston, Frederick. (1960). El pensamiento de Santo Tomás de Aquino. Ciudad de México: Fondo de Cultura Económica.

Forment, E. (2007). Santo Tomás de Aquino. Madrid: Editorial Ariel S.A.

Forment, E. (2009). Santo Tomás: su vida, su obra y su época. Madrid: Biblioteca de Autores Cristianos.

Gilson, Etienne. (2004). El espíritu de la Filosofía Medieval. Madrid: Editorial Rialp S.A. 
Gilson, Etienne. (2009). Introducción a la Filosofía de Santo Tomás de Aquino. Navarra: Ediciones Universidad de Navarra.

Hipona, San Agustín. (2010). Confesiones. Madrid: Editorial Gredos.

Hipona, San Agustín. (2011). Qué es el tiempo. Madrid: Editorial Trotta.

Marín, Roberto. (2006). Sociedad, política y protesta popular en la España musulmana. San José: Editorial Universidad de Costa Rica.

Morriones, Francisco. (1974). Teología de San Agustín. Madrid: Biblioteca de Autores Cristianos.

Villa-Real, Ricardo. (2003). Historia de Granada: acontecimientos y personajes. Madrid: Ediciones Miguel Sánchez.

Ross, David. (2013). Aristóteles. Madrid: Editorial Gredos.

San Agustín. (2009). La ciudad de Dios. Madrid: Biblioteca de Autores Cristianos.

Santa Biblia. (1979). Paso Texas: Editorial Mundo Hispano.

\section{Recibido: 19-Febrero-2015 Aceptado: 12-Mayo-2015}

Todos los derechos reservados. Universidad de Costa Rica. Esta revista se encuentra licenciada con Creative Commons Reconocimiento-NoComercial-SinObraDerivada 3.0 Costa Rica.

Correo electrónico: humanidades.eeg@ucr.ac.cr / Sitio web: http://revistas.ucr.ac.cr/index.php/humanidades 